\title{
In-Hospital Cardiac Death: Preventive Strategies
}

\section{Opinion}

The cardiac death is defined as death due to a cardiac disease, unknown origin, or when underlying disorder is unable to cause death by itself [1]. The in-hospital cardiac death, a specific type of cardiac death, has medical, epidemiological, administrative and ethical implications. In fact, it is consequence of health care and conceptually always preventable [2]. Almost all hospitalized patients are at risk to develop cardiac complications. Several acute pathophysiological disturbances such as hypoxemia, hypotension, renal dysfunction, electrolytic imbalances, neurological disorders and anaemia direct or indirectly act on cardiovascular system. Some cardiac/non-cardiac diagnostic or therapeutic intervention such as drugs, coronary catheterization, cardiac and non-cardiac surgery can also damage the heart.

There are three groups of patients according to type of therapy: 1) surgical; 2) medical; and 3) critically ill patients. Surgical patients have a higher risk for acute myocardial infarction (AMI) and acute pulmonary embolism (APE); medical patients frequently develop APE, acute heart failure (AHF) and cardiac arrest. Conversely, critically ill patients are at risk for any cardiac complication.

Acute pulmonary embolism is a cardiovascular emergency commonly observed in hospitalized patients with an associated mortality rate of 5-30\% [3]. The most effective and safe strategies preventing deep vein thrombosis and APE are: 1) evaluation and control of risk factors; 2) early mobilization; 3) mechanical methods; and 4) and thromboprophylaxis for those patients without contraindications $[4,5]$. In-hospital AMI has a incidence of $5 \%$ [6] and a mortality rate higher than 15\% [7]. Several therapies have been suggested for patients at risk such as those undergoing non-cardiac surgery [8]; however, no preventive strategy has demonstrated to be effective. Consequently, these patients should be managed as follow: 1) evaluation and control of risk factors; 2) perform the surgery according to current guidelines, including preoperative cardiovascular assessment and management [8]; 3 ) for those patients requiring emergency surgery, preoperative, transoperative and postoperative correction of hypotension, hypoxemia, electrolytic imbalance and metabolic disorders as soon as possible, as well as early antibiotic therapy; and 4) early correction of acute pathophysiological disturbances during and after surgical intervention such as hypotension, hypoxemia, pain and infections.

The one-year mortality rate of AHF is $20-30 \%$ [9]. Additionally, AHF is diagnosed in $40 \%$ of patients after an AMI; the risk of death is higher compared with those patients without AHF [10]. So that, for prevention of in-hospital AHF we suggest: 1) evaluation and control of cardiovascular risk factors; 2) perform the surgery according to current guidelines [8]; 4) continue with chronic cardiovascular therapy along time of hospitalization; 5) early correction of acute pathophysiological disturbances such as hypotension, hypoxemia, pain, electrolytic imbalance, anxiety/

Opinion
Volume 11 Issue 1 - 2018
Frank Daniel Martos-Benítez*
Intensive Care Unit, "Hermanos Ameijeiras" Hospital, Cuba
*Corresponding author: Frank Daniel Martos Benítez,
Intensive Care Unit, “Hermanos Ameijeiras” Hospital,
Fuentes Street at 367A, Guanabacoa, Havana, Cuba, Tel: +53
53925706; Email: fdmartos@infomed.sld.cu
Received: September 27, 2017 | Published: January 08,
2018

agitation, and infections; 6) avoid excessive intravenous fluid therapy; 7) early mobilization and rehabilitation; and 8) prevent/ treat renal dysfunction and hypertension. Annually, more than 200000 cases of in-hospital cardiac arrest (IHCA) are recognized in United State [11], and more than $50 \%$ of them occur into the intensive care unit [12]. Furthermore, the mortality rate at hospital discharge is $60-70 \%$ [13]. Usually, IHCA is secondary to hypoxemia or shock [14]; consequently, clinical deterioration can be anticipated. Cardiac origin can only be identified in $36 \%$ of patients with IHCA [15]. The current evidence suggest that many IHCA can be avoided with a closed surveillance, as well as an early, timely and correct therapy of acute pathophysiological disturbances associated with cardiac arrest. The rule of $5 \mathrm{H}$ and $5 \mathrm{~T}$ can help for this purpose [16].

In conclusions, there is not sufficient evidence to recommend any drug other than thromboprophylaxis for patients at high risk of APE. Treatment of the underlying disorder, closed surveillance, control and correction of acute pathophysiological disturbances, as well as an early diagnose and adequate therapy of cardiac complications are the mainstay of treatment for in-hospital cardiac death prevention. A randomized controlled trial to determinate the efficacy of preventive strategies is required.

\section{Source of Support}

Nil.

\section{Conflict of Interest}

There are no conflicts of interest.

\section{References}

1. Devereaux PJ, Yang H, Guyatt GH, Yusuf S, Leslie K, et al. (2006) Rationale, design, and organization of the PeriOperative ISchemic Evaluation (POISE) trial: a randomized controlled trial of metoprolol versus placebo in patients undergoing noncardiac surgery. Am Heart J 152(2): 223-230. 
2. Thygesen K, Alpert JS, Jaffe AS, Simoons ML, Chaitman BR, et al. (2012) Third universal definition of myocardial infarction. Circulation 126(16): 2020-2035

3. Pollack CV, Schreiber D, Goldhaber SZ, Slattery D, Fanikos J, et al. (2011) Clinical characteristics, management, and outcomes of patients diagnosed with acute pulmonary embolism in the emergency department initial report of EMPEROR: (Multicenter Emergency Medicine Pulmonary Embolism in the Real World Registry). J Am Coll Cardiol 57(6): 700-706.

4. Kahn SR, Lim W, Dunn AS, Cushman M, Dentali F, et al. (2012) Prevention of VTE in Nonsurgical Patients Antithrombotic Therapy and Prevention of Thrombosis, 9th ed: American College of Chest Physicians Evidence-Based Clinical Practice Guidelines. Chest 141(Suppl): e195S-e226S.

5. Gould MK, Garcia DA, Wren SM, Karanicolas PJ, Arcelus JI, et al. (2012) Prevention of VTE in Nonorthopedic Surgical Patients Antithrombotic Therapy and Prevention of Thrombosis, 9th ed: American College of Chest Physicians Evidence-Based Clinical Practice Guidelines. Chest 141(Suppl): e227S-e277S.

6. Kaul P, Federspiel JJ, Dai X, Stearns SC, Smith SC Jr, et al. (2014) Association of inpatient vs outpatient onset of ST-elevation myocardial infarction with treatment and clinical outcomes. JAMA 312(19): 1999-2007

7. Maestre A, Sánchez R, Rosa V, Aujesky D, Lorenzo A, et al. (2010) Clinical characteristics and outcome of inpatients versus outpatients with venous thromboembolism: findings from the RIETE Registry. Eur J Intern Med 21(5): 377-382.

8. (2014) The Joint Task Force on non-cardiac surgery: cardiovascular assessment and management of the European Society of Cardiology (ESC) and the European Society of Anaesthesiology (ESA). 2014 ESC/ ESA Guidelines on non-cardiac surgery: cardiovascular assessment and management. Eur J Anaesthesiol 31(10): 517-573.
9. Hummel A, Empen K, Dörr M, Felix SB (2015) De Novo Acute Heart Failure and Acutely Decompensated Chronic Heart Failure. Dtsch Arztebl Int 112(17): 298-310.

10. Auffret V, Leurent G, Gilardd M, Hacot JP, Filippi E, et al. (2016) Incidence, timing, predictors and impact of acute heart failure complicating ST-segment elevation myocardial infarction in patients treated by primary percutaneous coronary intervention. Internat J Cardiol 221: 433-442.

11. Mozaffarian D, Benjamin EJ, Go AS, Arnett DK, Blaha MJ, et al (2015) American Heart Association Statistics Committee and Stroke Statistics Subcommittee. Heart disease and stroke statistics-2015 update: a report from the American Heart Association. Circulation 131(4): e29-e322.

12. Mozaffarian D, Benjamin EJ, Go AS, Arnett DK, Blaha MJ, et al. (2016) Heart Disease and Stroke Statistics-2016 Update: A Report From the American Heart Association. Circulation 133(4): e38-360.

13. Monteleone PP, Lin CM (2012) In-Hospital Cardiac Arrest. Emerg Med Clin N Am 30: 25-34.

14. Kronick SL, Kurz MC, Lin S, Edelson DP, Berg RA, et al. (2015) Part 4: System of care and continuous quality improvement. 2015 American Herat Association guideline update for cardiopulmonary resuscitation and emergency cardiovascular care. Circulation 132(Suppl 2): S397-S413.

15. Syue YJ, Huang JB, Cheng FJ, Kung CT, Li CJ (2016) The Prognosis of Cardiac Origin and Noncardiac Origin in-Hospital Cardiac Arrest Occurring during Night Shifts. Biomed Res Int 2016: 4626027.

16. Monsieurs KG, Nolan JP, Bossaert LL, Greif R, Maconochie IK, et al. (2015) European Resuscitation Council Guidelines for Resuscitation 2015Section 1. Executive summary. Resuscitation 95: 1-80. 